EDTHORIAL

\title{
Bioética, autonomía y consentimiento informado en la investigación biomédica en tiempos de la COVID-19.
}

Bioethics, autonomy and informed consent in biomedical research in

times of COVID-19.

https://doi.org/10.54139/salus.v25i2.55

La ciencia es reconocida como el instrumento operacional que lleva de la mano a la investigación científica en la búsqueda de nuevos conocimientos. Los resultados obtenidos tienen un impacto sobre los individuos, la comunidad, el ambiente y la humanidad en general. La ciencia en general, la investigación y la experimentación en particular, no tienen valor absoluto, sino que se ponen al servicio de la persona, de la sociedad y del uso sustentable del ambiente. Aunque es reconocida la necesidad de la experimentación e investigación, el progreso científico no es motivo suficiente para justificar cualquier tipo de experimentación (1).

Debe prevalecer siempre el respeto a los derechos humanos y el bienestar de la persona, sujeto de investigación, sobre los intereses de la ciencia y de la sociedad (2). La producción de conocimientos y las metodologías utilizadas deben ser ejercidas por investigadores formados, responsables, con criterios científicos y no simples administradores de métodos y técnicas. En consecuencia, la bioética está enlazada con la investigación, fortaleciéndose a través de la reflexión interdisciplinaria.

La bioética es la ética de la ciencia que analiza los problemas morales que plantean los desarrollos de la biología, la biomedicina y la biotecnología (3). La bioética se ocupa de los conflictos éticos relacionados con la vida, estableciendo los valores y principios que deben regir las acciones humanas relacionadas con la biología, orientando los límites de la investigación científica aplicada a la vida. La bioética en el campo biomédico es la disciplina que se ocupa de lo concerniente a la manipulación de la biología y naturaleza del ser humano con el fin de salvaguardar los sujetos de investigación. No hay acción biomédica o en salud pública que escape de los cuatro principios básicos de la bioética: beneficencia, no maleficencia, justicia y autonomía (4).

El principio de beneficencia es la acción moral de hacer el bien y promover el bienestar, establece que las acciones deben ofrecer el máximo beneficio posible a la persona. La no maleficencia es el deber de que las acciones no produzcan daño ni conlleven riesgos innecesarios e implica prevención de potenciales efectos negativos.

La justicia en bioética es la que determina que los beneficios y las cargas que produzcan las actuaciones sean distribuidos de la manera más equitativa posible para todos los que las necesiten, rechazando cualquier tipo de discriminación. El principio de autonomía prioriza al individuo como el elemento moral fundamental, con los derechos y dignidad que le son intrínsecos como persona, con capacidad de deliberar y decidir sobre sí misma (5).

Estos principios se reflejan en el consentimiento informado, la protección de poblaciones vulnerables y en la conformación y acreditación de los comités bioéticos de investigación científica como lo señalan los códigos y normativas (El Código de Nuremberg,1947; Declaración de Helsinki, 1964; Informe Belmont, 1978; entre otros) (6).

El respeto por la autonomía del paciente o sujeto de investigación, la noción de toma de decisiones morales, supone que agentes racionales están involucrados en la toma de decisiones informadas y voluntarias lo cual significa, en el lenguaje común, que el sujeto tiene la capacidad de actuar intencionalmente, con comprensión y sin influencias controladoras de un acto libre y voluntario. Este principio es la base para la práctica del consentimiento informado y no debe ser considerado como un simple formalismo, sino que se debe explicar a la persona que participa en un proyecto de investigación acerca de su importancia, beneficios, y posibles efectos colaterales.

Ante una crisis pandémica, como la COVID-19, producida por un patógeno emergente, surgen obligaciones morales en el campo de la investigación biomédica para aprender lo más pronto posible sobre la biología, el comportamiento epidemiológico, la naturaleza e historia natural de la enfermedad que produce, la implementación de criterios clínicos y de diagnóstico y ensayos que evalúen estas pruebas, tratamientos o medidas preventivas como las vacunas.

Esto trae una avalancha de investigaciones biomédicas con elevadas inversiones públicas y privadas y el afán por investigar y obtener hallazgos que se acompañan de las obligaciones morales de colaboración internacional, compartiendo los resultados y avances de las investigaciones, además de la evaluación crítica de las mismas por expertos de la manera más precisa y transparente posible, para evitar multiplicación de esfuerzos redundantes o inútiles.

Ante la diversidad de tareas es posible que se haga muy difícil cumplir con los plazos habituales para la revisión de los ensayos clínicos con humanos por parte de los comités de bioética institucionales que tienden a aprobar en tiempos corto. Pero igual es indispensable respetar los derechos y protección del bienestar de los participantes, siguiendo la 
misma rigurosidad del consentimiento informado y el apego al principio de autonomía, al igual que los de beneficencia, no maleficencia, y justicia, a la vez que los estudios estén garantizados por su validez científica.

\section{REFERENCIAS BIBLIOGRÁFICAS}

1. Rubín de Celis Massa V. Bioética y bioseguridad en la investigación. Tradición, Segunda época. 2016, (13): 9-41. Disponible en: http://revistas.urp.edu.pe/index.php/Tradicion/ article/view/ 361/ 3572.

2. Ministerio del Poder Popular para Ciencia, Tecnología e Industrias Intermedias- MPPCTII. Código de Ética para la Vida 2011. Disponible en: https://www.locti.co.ve

3. Rotondo de Cassinelli MT. Introducción a la bioética. Rev Urug Cardiol. 2017, 32: 240-248

4. Beauchamp T, Childress J. Principios de ética biomédica. $4^{\mathrm{a}} \mathrm{Ed}$. Barcelona: Masson; 1999.

5. Kabbabe S. Bioética: ¿hay autonomía en pandemia? Prodavinci. 2020. Disponible en: https://prodavinci.com/bioetica-hayautonomia-en-pandemia/

6. Guzmán-Toro F. Bioética, derechos humanos y la investigación en seres humanos. Opción. 2014, 30 (73): 119-134

Yalitza Aular (D)

Instituto de Investigaciones Médicas y Biotecnológicas de la Universidad de Carabobo. IIMBUC.

Comisión Permanente de Bioética y Bioseguridad de la Universidad de Carabobo. CPBBUC.

Email: ydaular@uc.edu.ve / yaularz@gmail.com 